УДК 342.95

12.00.00 Юридические науки

СОВЕРШЕНСТВОВАНИЕ

ПРОФЕССИОНАЛЬНОЙ ПОДГОТОВКИ ГОСУДАРСТВЕННЫХ И МУНИЦИПАЛЬНЫХ СЛУЖАЩИХ

Иваненко Игорь Николаевич кандидат юридических наук, доцент кафедры административного и финансового права

Коваленко Екатерина Анатольевна студентка 2 курса юридического факультета Кубанский государственный агарный университет, Краснодар, Россия

В статье проанализированы этапы становления института государственной и муниципальной службы в российском государстве. В результате анализа выявлены проблемы в процессе реализации данного института и непосредственная взаимосвязь уровня профессиональной подготовки служащих и качества реализуемой службы.

Вследствие чего предлагаются пути совершенствования профессиональной подготовки государственных и муниципальных служащих

Ключевые слова: ГОСУДАРСТВЕННЫЙ СЛУЖАЩИЙ; МУНИЦИПАЛЬНЫЙ СЛУЖАЩИЙ; ПРОФЕССИОНАЛЬНАЯ ПОДГОТОВКА; ПРОБЛЕМЫ ГОСУДАРСТВЕННОЙ И МУНИЦИПАЛЬНОЙ СЛУЖБЫ

Doi: 10.21515/1990-4665-131-107
UDC 342.95

Legal sciences

\section{IMPROVING THE TRAINING OF STATE AND MUNICIPAL EMPLOYEES}

\author{
Ivanenko Igor Nikolaevich \\ candidate of law, docent of administrative and \\ financial department

\begin{abstract}
Kovalenko Ekaterina Anatolyevna student of Faculty of Law

Kuban State Agricultural University, Krasnodar, Russia
\end{abstract}

The article analyzes the stages of formation of Institute of state and municipal service in the Russian state. The analysis of the problems has identified in the process of implementation of this institution and the direct correlation of the level of professional training of employees and quality of the implementing service. We consequently suggest ways to improve the training of state and municipal employees

Keywords: PUBLIC SERVANT; MUNICIPAL CLERK; VOCATIONAL TRAINING; PROBLEMS OF STATE AND MUNICIPAL SERVICE

Первая часть третьего тысячелетия примечательна глобальными изменениями, происходящими в обществе, трансформацией его социальных институтов и организаций, которая характеризуется переосмыслением места и роли человека в современном мире, при этом затрагивая множество фундаментальных принципов бытия ${ }^{1}$. На сегодняшний день в российском обществе происходят глобальные изменения в экономике, политике, в социальной и многих других важных сферах, которые колоссально влияют на общество в целом, и под данным

1 Богатырева М.Р. Социальные ценности как основа профессиональнопедагогической деятельности / Вестник Башкирского государственного университета, 2006. T.11. №2. С. 122-124. 
воздействием в сферу обучения муниципальных и государственных служащих вносятся ряд изменений.

Местное самоуправление наиболее тесно связанно с населением. В субъектах Российской Федерации формируется инновационная система муниципального образования, которая ориентирована на реальный и устойчивый рост уровня жизни населения, на рост его активности в социальной сфере и на более полное раскрытие творческого потенциала, где важную роль играет самоорганизация и самоуправление всех членов местного сообщества. Вышеуказанное актуализирует задачу о создании качественного и инновационного состава кадров муниципальных служащих.

Формирование и развитие муниципального служащего сегодня влечет за собой необходимость решения органами местного самоуправления кардинально новых задач. Изменение в содержании целей, задач, функций, полномочий и предметов ведения местных органов представительной и исполнительной власти привело к значительному усложнению и увеличению поля деятельности государственных и муниципальных служащих. Успех проводимых сегодня реформ прямо пропорционально зависит от того, будет ли сформирован кадровый корпус муниципальных служащих, который сможет отвечать современным требованиям, предъявляемым государственной кадровой политикой. В рамках данных условий проводится исследование качественной характеристики кадрового потенциала муниципальной службы, поиск путей в направлении его совершенствования представляются принципиально важными и актуальными.

Для эффективной ликвидации вопроса совершенствования подготовки, переподготовки и повышения квалификации государственных и муниципальных служащих, а также для формирования данного кадрового корпуса важно осуществлять наблюдение за изменениями в 
различных областях жизни общества на данном этапе, важно иметь высокий уровень профессиональной подготовки и эрудиции, так как уровень и степень профессиональной подготовки - является одним из наиболее действенных способов решения поставленной задачи.

Также для эффективного повышение уровня профессионализма повсеместно необходимо развивать кадровый потенциал государственной и муниципальной служб, что характеризуется индивидуальными чертами Стратегии инновационного развития РФ на временной промежуток до 2020 г. как всероссийской программы государственного управления и относящийся к данным кардинальным изменениям в профессиональной среде специалистов в области социального управления. При решении данной проблемы важное место остается за сферой дополнительного образования, конкретно в системе повышения квалификации. Анализ говорит о том, что в силу проводимых реформ (местного самоуправления и административной), а также по средствам стабильно проводимой ротации государственных гражданских и муниципальных служащих необходимость в подготовке кадров для органов государственной власти и местного самоуправления в будущем будет изрядно расти. На основании чего проявляется необходимость перманентного повышения квалификации в сфере дополнительного профессионального образования государственных гражданских и муниципальных служащих.

Одновременно результаты исследований говорят о сложившейся в государстве системе дополнительного профессионального образования государственных гражданских и муниципальных служащих, которая на данном этапе не готова к решению данной задачи на высоком уровне. Она не отвечает в полной мере современным требованиям изменившихся обстоятельств, какими являются процессы, которые свойственны транзитивному обществу, a eе масштабы недостаточны для удовлетворения текущих и перспективных пожеланиях потребителей 
образовательных услуг в повышении квалификации и переподготовке кадров для сферы государственного и муниципального управления.

Согласно мнению специалистов, изучивших данный вопрос, одной из причин данного состояния дел является то, что муниципальную или государственную службу в России, обычно, осуществляют специалисты, которые в большинстве случаев не получили базового профессионального образования в сфере управления, а именно управления в социальной сфере. Что позволяет определить главное противоречие в обеспечении кадрового потенциала сферы государственного и муниципального управления: данная система подвержена дефициту профессиональных компетентных в вышеуказанных вопросах специалистах. Восполнить данные пробелы, в определенной степени, может введение системы дополнительного профессионального образования, которую важно рассматривать в данных условиях как наиболее важный институт профессионализации кадров, как фактор развития профессиональной компетентности государственных гражданских и муниципальных служащих. На нее возложены такие важные функции, как решение задач профессионального развития государственных и муниципальных служащих в соответствии с современными требованиями к их служебной деятельности и формирование их профессиональной компетентности в соответствии с современными требованиями к качеству профессиональной подготовки, за что предусмотрена серьезная ответственность. В связи с этим, имеющиеся подходы к системе дополнительного профессионального образования в российском образовании не могут применяться в нестандартных условиях повышения квалификации государственных гражданских и муниципальных служащих, обусловленных перманентно осуществляемыми переменами в российском обществе и их базовой профессиональной подготовкой. 
Нестандартной ситуацией можно считать, во-первых, необходимость повышения уровня компетентности по вопросам профессии специалистов, которая была создана исключительно практическим путем, исключая базовую профессиональную подготовку по направлению обучения, связанному с государственным и муниципальным управлением. Вовторых, необходимостью поиска нераскрытых резервов и новых путей повышения эффективности и результативности, связанных с развитием сферы дополнительного профессионального образования, которое основывается на формировании инновационных организационных структур непрерывного обучения или улучшении уже существующих, что обусловлено транзитивными процессами, которые происходят в Российской Федерации. Не менее важным является вопрос совершенствования подготовки государственных и муниципальных служащих, которые поступили и были приняты на службу впервые.

На наш взгляд, для эффективного решения поставленных выше проблем нужно разработать профессионально- квалификационную модель и критерии оценки муниципальных служащих. Оценка складывается из сравнения познаваемого с тем, что может выступать в качестве идеала. Обобщая вышесказанное можно смоделировать муниципального служащего, который определит профессионализм и квалификацию работника. Так как муниципальная служба включает в себя обязательную работу с населением, включение профессиональной характеристики и личностных особенностей будет играть важную роль². В научной литературе можно найти различные методы и подходы к оценке персонала. Однако все они являются субъективными т.к. решение зачастую зависит от того, кто использует данный метод или от экспертного состава.

${ }^{2}$ Васильев А.В. Местное самоуправление: опыт, проблемы и перспективы. М.: Граница, 2002. 
В условиях изменчивого мира, динамичного и непредсказуемого времени традиционные подходы к системе повышения квалификации не приводят к гибкости и оперативности развития данной среды, что является крайне актуальным для периода реформ сферы государственного и муниципального управления. На наш взгляд, данную точку зрения можно рассматривать как наиболее перспективный подход при решении вопросов повышения квалификации государственного и муниципального служащего в условиях современного общества, характеризующихся трансформирующимся обществом и образованием, в том числе и его элементом, системой дополнительного профессионального образования.

Считаем, что, в качестве обоснованного научного подхода в системе дополнительного профессионального образования государственных и гражданских служащих нужно рассматривать адаптивный подход, который наиболее полно отвечает особенностям транзитивного общества в России, а также инновационному развитию российского образования. В поиске путей, которые должны совершенствовать систему повышения квалификации государственных и муниципальных служащих в условиях активных перемен в обществе, значительная роль, на наш взгляд, принадлежит идее адаптивного повышения квалификации специалиста.

Адаптивное повышение квалификации может учитывать индивидуальные особенности и потребности государственного и муниципального служащего, находящегося на обучении, обоснованные отсутствием базового образования необходимого для данной сферы. Оно может быть направленным на решение их профессиональных проблем, интересов, возможностей в аспекте будущего жизненного и профессионального успеха, учитывая осуществляемые изменения общественной жизни. Поиски наиболее подходящего потребностям изменяющегося общества в РФ научного подхода и новейшего образования к повышению квалификации государственного и 
муниципального служащего в большинстве случаев востребованы на практике.

Важность соблюдения государственной инновационной политики в рамках государственного и муниципального управления сделала актуальной проблему формирования профессионально компетентного специалиста и как следствие стал необходимым поиск эффективных подходов к повышению его квалификации. Данная актуализация объясняется такими обстоятельствами, как предпосылки к разработке адаптивного подхода к повышению квалификации государственного и муниципального служащего:

- увеличенными требованиями, которые предъявляются к структуре повышения квалификации, что связано с процессами трансформации, происходящими в современном обществе и, соответственно, в сфере образования;

- невысоким уровнем подготовки специалистов сферы государственного и муниципального управления для продуктивного осуществления управленческой деятельности соответственно с перманентно наступающими переменами, которые обусловлены инновационным характером социально-экономического развития российского общества и государства;

- наличием потенциала адаптации в системе повышения квалификации по подготовке специалистов сферы государственного и муниципального управления к деятельности в новых условиях, которые характеризуются процессами трансформации;

- повышающейся необходимостью в специалистах сферы государственного и муниципального управления на практике, которые готовы к осуществлению инновационной деятельности в отношении государственного и муниципального управления и приспособленных к адаптации в среде постоянно изменяемого общества; 
- инновационным развитием в рамках дополнительного профессионального образования, его многообразием, многоплановостью, а также важностью адаптации в системе повышения квалификации к постоянным переменам и др. Суть адаптации состоит в том, что адаптивное повышение квалификации государственного и муниципального служащего необходимо рассматривать, не только, как процесс образования, который предназначен для гибкого учета особенностей обучения каждого слушателя (различных возрастов, стажа, квалификации и т. д.), но и как систему повышения квалификации , которая создана для обеспечения адаптации государственного и муниципального служащего к ежедневно динамично изменяющейся среде образования, которая сформирована под направленным воздействием непосредственно общества и государства.

В фундаменте повышения квалификации по средствам адаптации лежат работы исследователей данной сферы, таких как: Г. К. Зайцева, Н. А. Заруба, Н. П. Капустина, Н. В. Ковша, В. А. Мильдопа, А. М. Моисеева, Н. Е. Попова, Т. И. Шамовой, Е. А. Ямбурга и др. Особый интерес вызывают работы . К. Бабанского, В. П. Беспалько, Г. К. Селевко, в которых приводятся разнообразные аспекты адаптивного учебного процесса.

Учитывая исследования, проведенные в рамках адаптивного подхода, представляется возможным определить сущность адаптивного повышения квалификации государственного и муниципального служащего. Это и адаптивная образовательная среда, развивающаяся и развиваемая специалиста; и это сфера образования, по средствам которой можно максимально, по сравнению с неадаптивной системой, развить у каждого слушателя его оптимальное интеллектуальное развитие в соответствии со способностями и возможностями, и что не менее важно потребностями государства и общества; это и адаптивный процесс, 
который направлен на складывание профессионально компетентности служащего сферы государственного и муниципального управления, учитывая потребностей конкретной личности, а также государства и общества. По различным мнениям, основная функция адаптивного ПК сводится к тому, что она наиболее приближена к потребностям специалиста; что образовательная среда, которая создается в адаптивной системе ПК, совершенно не обеспечивает приоритеты излишней заботы о специалисте и не затормаживает процесс формирования нужных ему профессиональных компетенций. Однако, она, напротив, учитывая индивидуальные черты специалиста, приспосабливается к нему и деликатно способствует его профессиональному развитию в будущем. Адаптивная система повышения квалификации предназначена для максимальной помощи всем слушателям, при достижении ими необходимого профессионального развития, учитывая его возможности и интересы, а также опираясь на потребности государства и общества.

Важно отметить, что современная система адаптивного повышения квалификации имеет общие особенности, которые обусловлены процессом трансформации в обществе и интенсивным развитием рыночной экономики: научно-образовательная новизна, практическая реализуемость. Данной системе также присущи специфические особенности, которые вызваны характером процессов, происходящих в образовании, на сегодняшний день. В качестве особенностей также можно рассматривать адаптивные технологии повышения квалификации, к которым мы относим, прежде всего, интерактивные.

Проведенные исследования свидетельствуют, о том, что взрослый человек «держится» за свои, устоявшиеся в процессе социализации, ценности, жизненные и профессиональные стереотипы до тех пор, пока к нему не приходит осознание важности и необходимости отказа от некоторых из них. Интерактивное обучение способствует активации 
важного опыта управления государственного и муниципального служащего, а также правильному становлению его профессионального мышления, приобретению конструктивных позиций в отношении нововведений, творческому подходу к оптимизации чужого опыта и т. п. К интерактивным технологиям обучения адаптирующего свойства относят модерацию, кейс-технологию, коллективный способ обучения, технологию проектного обучения, технологию мастерских, деловые игры и другие. Обобщая различные научные формулировки понимания интерактивного обучения как одного из способов познания, который осуществляется в формах обоюдной деятельности обучающихся и обучаемых, где участники образовательного процесса взаимодействуют друг с другом, мы хотели бы охарактеризовать сущность адаптивного взаимодействия в процессе повышения квалификации обучающихся в сфере интерактивного обучения. На наш взгляд, в рамках адаптивного повышения квалификации государственного и муниципального служащего интерактивные методы, обеспечивают процесс взаимодействия субъектов. Его можно интерпретировать как комплекс связанных между собой во времени и пространстве видов деятельности, которые позволяют осуществлять адаптирующее и адаптивное взаимодействие на основе опыта и знания участников образовательного процесса, что служит также источником их взаимообучения и взаимообогащения.

Обобщая вышесказанное, можно сделать вывод, что, на сегодняшний день профессиональная подготовка муниципальных и государственных служащих, не может быть эффективной без соответствующего научнометодического обеспечения, без разработки профессиональноквалификационной модели и критериев оценки муниципальных и государственных служащих и, конечно, без объединения усилий в этом направлении научных сотрудников, преподавателей, самих муниципальных служащих. 


\section{Список использованной литературы:}

1. Указ Президента Российской Федерации «О государственном заказе на переподготовку и повышение квалификации государственных служащих» от 7 февраля 1995 года № 103.

2. Указ Президента Российской Федерации «О дополнительных мерах по подготовке государственных и муниципальных служащих» от 3 сентября 1997 года №983.

3. Федеральный закон «О муниципальной службе в РФ» от 02.03.2007 № 25-Ф3.

4. Постановление Правительства Российской Федерации «Об организации переподготовки и повышении квалификации государственных служащих федеральных органов исполнительной власти» от 13 сентября 1994 года №1047.

5. Богатырёва М. Р., Масягутова А. Н. Структурное формирование трудовых ресурсов : сб. науч. трудов Sworld. - 2013. - Т. 39. - № 1. С. 51-53.

6. Богатырева М.Р. Социальные ценности как основа профессиональнопедагогической деятельности / Вестник Башкирского государственного университета, 2006. T.11. №2. С. 122-124.

7. Борисов А.Н. Комментарий к Федеральному закону от 06.10.2003 г. № 131-Ф3 «Об общих принципах организации местного самоуправления в РФ». - М: Деловой двор, 2010. С. 179.

8. Бурлачук Л.Ф., Морозов С.М. Словарь-справочник по психодиагностике СПб.: Изд-во «Питер», 2000. (Серия «Мастера психологии»).

9. Васильев А.В. Местное самоуправление: опыт, проблемы и перспективы. М.: Граница, 2002.

10. Веселков А.Ф. К вопросу о надежности результатов оценочных процедур и эффективности их использования / Журнал прикладной психологии, 2001, №3 11. Марченко И.П. Особенности формирования кадрового потенциала государственной (муниципальной) службы в современной России: Монография. - Новосибирск, 2010. С. 35.

12. Заруба Н. А. Адаптивный подход в управлении образованием: принципы управления // Профессиональное образование в России и за рубежом. - 2012. - № 2. - C. 75-79.

13. Стратегия инновационного развития Российской Федерации на период до 2020 года [Электронный ресурc]. — URL: www.strategy2020.rian.ru/.

14. Неклюдова Л. В. Адаптивная курсовая подготовка в системе повышения квалификации педагогических работников : автореф. дис. ... канд. пед. наук. Ижевск, 2005.

15. Штуль Е. В. Развитие адаптивных форм управления в муниципальном общеобразовательном учреждении // Ярославский педагогический вестник. — 2009. — № 2 (59). - C. 90-93

\section{References}

1. Ukaz Prezidenta Rossijskoj Federacii «O gosudarstvennom zakaze na perepodgotovku i povyshenie kvalifikacii gosudarstvennyh sluzhashhih» ot 7 fevralja 1995 goda № 103 .

2. Ukaz Prezidenta Rossijskoj Federacii «O dopolnitel'nyh merah po podgotovke gosudarstvennyh i municipal'nyh sluzhashhih» ot 3 sentjabrja 1997 goda №983.

3. Federal'nyj zakon «O municipal'noj sluzhbe v RF» ot 02.03.2007 № 25-FZ. 
4. Postanovlenie Pravitel'stva Rossijskoj Federacii «Ob organizacii perepodgotovki i povyshenii kvalifikacii gosudarstvennyh sluzhashhih federal'nyh organov ispolnitel'noj vlasti» ot 13 sentjabrja 1994 goda №1047.

5. Bogatyrjova M. R., Masjagutova A. N. Strukturnoe formirovanie trudovyh resursov : sb. nauch. trudov Sworld. - 2013. - T. 39. - № 1. S. 51-53.

6. Bogatyreva M.R. Social'nye cennosti kak osnova professional'no- pedagogicheskoj dejatel'nosti / Vestnik Bashkirskogo gosudarstvennogo universiteta, 2006. T.11. №2. S. 122124.

7. Borisov A.N. Kommentarij k Federal'nomu zakonu ot 06.10.2003 g. № 131-FZ «Ob obshhih principah organizacii mestnogo samoupravlenija v RF». - M: Delovoj dvor, 2010. S. 179.

8. Burlachuk L.F., Morozov S.M. Slovar'-spravochnik po psihodiagnostike - SPb.: Izdvo «Piter», 2000. (Serija «Mastera psihologii»). 2002.

9. Vasil'ev A.V. Mestnoe samoupravlenie: opyt, problemy i perspektivy. M.: Granica,

10. Veselkov A.F. K voprosu o nadezhnosti rezul'tatov ocenochnyh procedur i jeffektivnosti ih ispol'zovanija / Zhurnal prikladnoj psihologii, 2001, №3 11. Marchenko I.P. Osobennosti formirovanija kadrovogo potenciala gosudarstvennoj (municipal'noj) sluzhby v sovremennoj Rossii: Monografija. - Novosibirsk, 2010. S. 35.

12. Zaruba N. A. Adaptivnyj podhod v upravlenii obrazovaniem: principy upravlenija // Professional'noe obrazovanie v Rossii i za rubezhom. - 2012. - № 2. - S. 75-79.

13. Strategija innovacionnogo razvitija Rossijskoj Federacii na period do 2020 goda [Jelektronnyj resurs]. — URL: www.strategy2020.rian.ru/.

14. Nekljudova L. V. Adaptivnaja kursovaja podgotovka $\mathrm{v}$ sisteme povyshenija kvalifikacii pedagogicheskih rabotnikov : avtoref. dis. ... kand. ped. nauk. — Izhevsk, 2005.

15. Shtul' E. V. Razvitie adaptivnyh form upravlenija $v$ municipal'nom obshheobrazovatel'nom uchrezhdenii // Jaroslavskij pedagogicheskij vestnik. — 2009. — № 2 (59). - S. 90-93 